\title{
Satish Dhawan: Provider of a firm structure to ISRO and a major contributor to 'ISRO culture'
}

\author{
B. N. Suresh* \\ Indian Institute of Science and Technology, Thiruvananthapuram 695 547, India
}

SATISH Dhawan was a multi-faceted personality. He was a great mathematician, an eminent aerospace scientist, engineer, teacher, technologist, an outstanding researcher, administrator par excellence and more than anything else a very good human being. He specialized in experimental fluid dynamics, and established the country's first supersonic wind tunnel at the Indian Institute of Science (IISc), Bangalore. His research interests were on separated boundary layer flows, three-dimensional boundary layers and trisonic flows. Dhawan's education too is interesting with two Bachelor's degrees, one in physics and mathematics, and one in mechanical engineering from Punjab University in Lahore (now in Pakistan), a Master of Arts in English literature, a Master of Science in aerospace engineering at the University of Minnesota, an aeronautical engineering degree and also a double $\mathrm{PhD}$ in mathematics and aerospace engineering from the California Institute of Technology (Caltech, USA) under the guidance of Hans W. Liepmann, a pioneer in fluid mechanics research, who later on became Director at the Graduate Aerospace Laboratories at Caltech (GALCIT). Liepmann was an excellent teacher and also a good researcher.

Subsequent to the untimely death of Vikram Sarabhai in December 1971 at an young age of 52 years, M. G. K. Menon who was then the Director of the Tata Institute of Fundamental Research, Mumbai (1966-75), was asked to take charge as the Chairman of Indian Space Research Organisation (ISRO) and he steered the activities of ISRO for a brief period of nine months. Menon was certain that he will be holding charge of ISRO only as a stop-gap arrangement and he had felt that Dhawan was the man for the same ${ }^{1}$. Dhawan was on a sabbatical at Caltech in 1971-72, and he got a call from the then Prime Minister Indira Gandhi to return to India and take charge of the Indian space programme. Dhawan considered various aspects of taking over the space programme and finally agreed. While agreeing to the request he pressed for two conditions, namely to have ISRO headquarters at Bengaluru and be allowed to continue as Director of IISc, the position he was holding at that time. Both these conditions were agreed to. Dhawan returned to India after his sabbatical at Caltech, USA in 1972. After his return he

*e-mail: byranasuresh@gmail.com was appointed as Chairman of ISRO, Chairman of the Space Commission and also Secretary to Government of India in Department of Space (DoS). He was also allowed to continue as Director IISc.

The vision of Vikram Sarabhai, the founding father of ISRO, was to transform India into a space power. He strongly believed that the advanced technologies of space like remote sensing, communication and meteorology can be gainfully utilized to find solutions to many of the problems faced by a big country like India. He was also certain that it is essential to undertake end-to-end development, so that the country can be totally self-reliant in the domain of space. When Dhawan took the mantle of ISRO, Sarabhai had already established the Thumba Equatorial Rocket Launching Station (TERLS) on the shores of Thumba, Thiruvananthapuram, to enable both Indian and foreign scientists to carry out experimental studies of a large region of atmosphere using sounding rockets. Sarabhai had also set up the Space Science and Technology Centre (SSTC) for development of technologies needed mainly for launch vehicles. In the initial period of the SSTC, small group of scientists were working in the Satellite Systems Division (SSD) for the development of satellite technologies at Thiruvanthapuram. Subsequently, the satellite activities were moved to the Satellite Centre at Bangalore, which is now named after U. R. Rao, the architect of satellite activities in the country. At SSTC, a large number of young scientists recruited mostly from Indian institutions and universities were actively engaged in the development of various technologies needed for launch vehicles. There was rigorous healthy competition amongst engineers in several technology developments and this was deliberately encouraged by Sarabhai, as he believed that competition would help to accelerate the development of technologies needed for a launch vehicle.

Dhawan became Chairman of ISRO at a crucial juncture and seamlessly continued with the programmes initiated by Sarabhai. Dhawan was firm that India's space programme has to be relevant to society. Also the technical progress has to reach every person for the upliftment of the poor. Soon after he took charge, Dhawan realized the need for a proper structure to ISRO and accordingly, implemented a concrete and dynamic 
management structure to Indian space research programme. He introduced several important management concepts in a progressive manner. He strongly felt the need to bring ISRO under the Government and thus established DoS. The remarkable progress and the string of successes achieved by ISRO are attributed to so called 'ISRO culture'. It is difficult to define this culture in so many words. But in my opinion a number of management decisions made by Dhawan during the initial period of ISRO helped vastly to evolve this 'ISRO culture'. As a young engineer I was witness to all these developments. I want to highlight some of the well-structured management concepts introduced by Dhawan.

(a) Introducing well-defined organizational structures in launch vehicle, spacecraft and application centres.

(b) Defining the project structure for our first launch vehicle SLV-3 and also for Aryabhata projects.

(c) Identification of project teams with clear definition of tasks activity-wise. Young scientists (mostly fresh from Indian institutions) were appointed as team members with well-defined responsibilities.

(d) Constitution of Project Management Boards (PMBs) and Project Management Councils (PMCs) with proper definition of roles and responsibilities for the smooth management of projects.

(e) Introduction of rigorous review systems at different phases of the project and inviting subject specialists from academia and other R\&D centres. This also helped to bring in total transparency in the system.

(f) Partnering with industry for the realization of hardware from the beginning of a project (host of the SLV-3 hardware were produced by Indian industries from the inception).

(f) Setting up of a Joint Consultative Machinery (JCM), presided by the Chairman of ISRO, a forum to engage the employees and to sort out all outstanding issues amicably.

There are many more such management decisions made by Dhawan. He gave full freedom to project directors and enabled them to take final decisions on all matters related to the project. This immensely helped to complete the tasks of the complex projects within the stipulated schedule and reasonably within the projected cost. He also gave a lot of importance to indigenous industries for ISRO projects right from the beginning; today, more than 500 industries, both public and private, small and big, manufacture a wide range of space-quality hardware for ISRO. On the administrative side, Dhawan brought seamless integration of purchase, accounts, etc. in the management of projects for the smooth and speedy progress of tasks. The senior administrative functionaries were made members in management forums and their views were factored in decision-making. This helped the administrative personnel to understand the complexities of the project and also their role in progressing the tasks. These officials in management forums always provided the right inputs on relevant rules and regulations which were appropriately considered in decision-making.

Dhawan, an eminent academician always believed in having strong links with academia and hence introduced a programme named RESPOND; a sponsored research programme of ISRO. The objective was to enhance the academic base, encourage quality research and development in Indian universities/institutions, undertake research in areas which are relevant to the space programme, generate human resources and even expand the infrastructure base. He took keen interest in establishing Space Technology Cells (STCs) in many premier educational institutions. The entire STC programme has been successful and provided valuable inputs to our programmes.

All these management decisions were made in the initial period of Dhawan's Chairmanship in the early 1970s. He laid down his office in 1984 after providing dynamic leadership to ISRO for almost 12 years. He provided a firm foundation for all programmes of ISRO. He also defined unambiguous future directions. As on 2020, in the last three and half decades, the programmes of ISRO have multiplied many fold, with several accomplishments like the operationalization of launch vehicles, spacecraft, including Chandrayaan and MARS mission. The entire country has benefitted vastly from its application programmes on natural resources survey, weather monitoring, tele medicine, tele education, disaster management, etc. Today, ISRO is considered as one of the jewels in the Government. While the progress of ISRO is substantial, it is to be noted that the various management techniques introduced by Dhawan have stood the test of time and are being followed even today in ISRO, with some minor variations here and there. We all have to remember with gratitude the contributions of Dhawan, the legend who introduced these core management concepts which have remained intact even after four decades. This certainly demonstrates the robustness of the systems he introduced. One thing is certain; while it was Sarabhai's vision which gave birth to the Indian space programme it was Dhawan's administrative and management skills which helped transform of ISRO into a world-class organization.

There is always a debate on the ISRO Chief holding three important positions, viz. Chairman of ISRO, Chairman of the Space Commission and Secretary of DoS simultaneously. This question was well explained by Dhawan himself. He says ${ }^{2}$ it was a conscious decision to club all three vital positions. His view was that the Secretary of DoS has to be the Chairman of the Space Commission and it was decided by the government. ISRO is a research group, not just the management system. Once it was decided that ISRO has to be a Government organisation, it must be a full set up and come under Department 


\section{SATISH DHAWAN BIRTH CENTENARY}

of Space, DoS. ISRO being a research organisation he was reluctant to convert ISRO into DoS. Therefore, he strongly felt that ISRO has to continue as a research organization and it should have a Chairman. So ISRO remained as such.

The next question is who will head ISRO. To quote Dhawan': 'not difficult to imagine a typical management chart: that you have a Chairman in ISRO who reports to Secretary DoS, who is no longer connected with people in daily life, talking to scientific people in daily life, talking about matters not only in money management but also technical issues. Very rapidly, we would then have a cleavage and the pattern would begin to change. Although ISRO is a research organisation, it is government organisation. Why should a government organisation with people of calibre in ISRO Centres or whole lot of people be participatory in decision making? The Chairman of the Space Commission is really an interface between the DoS and the Government of India. Space Commission advises the Prime Minister and the Cabinet and in that role an informed person will also be running ISRO and knowing the feel of it.'

Holding these three posts concurrently guaranteed seamless alliance among various activities like conceptualization, getting approval of programmes, timely resolutions of conflicts and adhering to the projected schedules. No doubt, the design of this architecture by Dhawan was indeed original and innovative. Such was his dynamism and commitment to work.

One can visualize that the concept of unity command he introduced in the beginning by having all three offices of Secretary DoS, Chairman, Space Commission and Secretary DoS under one command contributed significantly to the smooth operation of all ISRO projects. Various decisions he made on projects, project management formations, participation of different stakeholders in these different forums brought the culture of participatory management. The openness and transparency was brought by introducing active horizontal participation in all our review systems and also inviting the external experts from academia, R\&D institutions and industry in many of our reviews on a continuous basis. All these management decisions made by Dhawan have resulted into a string of successes in ISRO, in the last four decades, including the accomplishment of many complex missions. This, I believe is the 'ISRO culture' and I have no hesitation in saying that all the successes of ISRO are due to this unique culture. This certainly is a major contribution of Dhawan to ISRO.

Dhawan always believed in an open and robust review system and introduced this in all our projects. Apart from various time-to-time reviews, Dhawan used to allot time to review the status of all major projects and R\&D programmes once in a month by visiting the major centres. All project personnel used to look forward to such reviews and carry out a lot of preparation. They used to make comprehensive presentations on the status of projects and also highlight the critical areas. The review would prolong for several hours and at times even for two days, and there used to be intense discussions. Dhawan encouraged everyone, including the younger generation to participate actively in such discussions. He used to conclude by giving constructive suggestions and identifying the necessary actions for the smooth and timely completion of the projects. Such reviews also used to provide a lot of motivation to the entire team, particularly the youngsters.

Dhawan gave greater emphasis during his tenure to rural education, remote sensing and satellite communication, and also to the rapid development of the country. In order to hasten the development, he promoted pioneering experiments in all these areas. His vision was in establishing operational systems like the INSAT series, the Indian Remote Sensing Satellite (IRS) Series and also transportation vehicles which carry these spacecraft. In order to have smooth interface with the user agencies, he visualized setting up formal institutional frameworks like the Planning Committee for the National Natural Resources Management System (NNRMS) with all stakeholder agencies, and the mandate was to provide directions for space-based remote sensing capabilities for the country; the INSAT Coordination Committee to oversee and advise on matters related to space communication, broadcasting and meteorology. Regarding space science, he constituted the Advisory Committee on Space Sciences (ADCOS) to review on a continuous basis and provide development guidelines. All these institutional frameworks contributed significantly to ensure the smooth interface with all stakeholders and thus accelerate the developmental works in all these areas. Meanwhile he also attached equal importance for the development of transportation vehicles like polar satellite launch vehicle (PSLV) and geosynchronous launch vehicle (GSLV) to position our spacecraft in their defined orbits. He steered these activities with rigorous reviews on a regular basis and thus succeeded in positioning India in the league of space-faring nations.

As young engineers in 1970s, each one of us used to look for opportunity to present part of our development in the reviews conducted by Dhawan. I got my first opportunity in early 1975, in one of the status reviews of SLV3 to present the progress of control systems. I had spent considerable time to prepare for the presentation and also to prepare the answers for possible questions. He used to ask razor-sharp questions and we did not want to get caught on the wrong foot. I was happy to note that the presentation and discussions went smoothly and he was satisfied. I also noticed that in subsequent reviews at VSSC, he used to seek my opinion on some of the issues, which itself was a good recognition. This is how he used to encourage all young scientists and engineers, and motivate them to contribute their best to the programmes. 
As a young engineer those days, I had only a few opportunities to interact with Dhawan. I want to recall one or two such interactions with him from which I learnt important lessons. One important decision he made in 1980 , in a way set my future directions in ISRO. I had returned from my doctoral studies in 1978 and I was posted back in my old control and guidance division at VSSC. Having specialized in electro hydraulic control systems, I was keen to work on the development of engine gimbal control system for PSLV. At that time there was a competition to undertake this development between Vikram Sarabhai Space Centre (VSSC) and the Liquid Propulsion Systems Centre (LPSC), as the propulsion-based controls systems were shifted to LPSC. When this issue was brought to the notice of Dhawan, he set up a high power committee for review and recommendation. Once the committee submitted its recommendations, Dhawan decided that VSSC will undertake the development of gimbal actuation system for PSLV and entrusted the responsibility to me. He also suggested a unique management structure for this development by setting up the 'Gimbal Actuation Task Team' (GIST) to carry out the work under this set-up. Later on, whenever he met me he used to call me as the GIST person.

Much later in March 2001, I got another opportunity to meet Dhawan. I was asked by K. Kasturirangan, the then Chairman of ISRO, to brief both Dhawan and R. Narasimha on the details of the abort of GSLV D1 flight. After spending almost two hours and facing his sharp questions on many technical issues, Dhawan spent another half an hour stressing the need to carry out space developments, so that ultimately it should serve the common man and society. I could see his deep concerns towards the welfare of the common man and society. It was indeed a good lesson.

Dhawan was a great admirer of birds and took keen interest to study different kinds of birds and their dynamics. He often used to mention Siberian birds and was an active researcher on birds. His research included the framework for bird flying, structure and action of muscles, wing profiles, and the flapping profile of different birds. Dhawan's love for nature, and his interest in birds, led to the publication of a book Bird Flight authored by him. He also dreamt about developing the flapping wing aircraft with high manoeuvrability.

In January 2002, we lost one of our most distinguished scientists, who provided a sound base and a unique culture to ISRO, which transformed it into a world-class organization. In his birth centenary year, the entire space community remembers Dhawan as a person who provided a stable foundation for the 'ISRO culture'. The edifice we have built over the last four decades and the success stories of many missions, including a couple of complex projects have amply demonstrated the soundness of the structure provided by Dhawan. He was certainly an excellent researcher, but also an administrator par excellence. We were extremely lucky to have him as the chief of ISRO at the right time during its formative years.

1. Menon, M. G. K., ISRO after Vikram Sarabhai. In From Fishing Hamlet to Red Planet, Harper Collins Publishers, India, 2015, pp. 13-19.

2. Manoranjan Rao, P. V., 'The Architect', based on the interview with Prof. Satish Dhawan. In From Fishing Hamlet to Red Planet, Harper Collins Publishers, India, 2015, pp. 43-52.

doi: $10.18520 / \mathrm{cs} / \mathrm{v} 119 / \mathrm{i} 9 / 1457-1460$ 